\title{
THE FALSTF LAST-FLIGHT COMPUTER PROGRAM
}

\author{
R. L. Childs \\ Computational Physics and Engineering Division \\ Oak Ridge National Laboratory* \\ P.O. Box 2008 \\ Oak Ridge, Tennessee USA 37831-6370
}

To be presented at

ANS 1996 Radiation Protection and Shielding Division Topical Meeting Advancements and Applications in Radiation Protection and Shielding for the Advancements in Discrete Ordinates Methods Session April 21-25, 1996

Cape Cod, Massachusetts

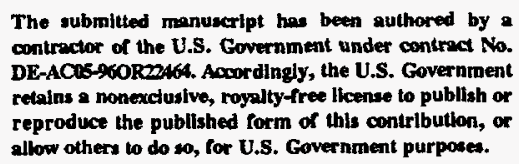

\section{DISCLAIMER}

\begin{abstract}
This report was prepared as an account of work sponsored by an agency of the United States Government. Neither the United States Government nor any agency thereof, nor any of their employees, makes any warranty, express or implied, or assumes any legal liability or responsibility for the accuracy, completeness, or usefulness of any information, apparatus, product, or process disclosed, or represents that its use would not infringe privately owned rights. Reference herein to any specific commercial product, process, or service by trade name, trademark, manufacturer, or otherwise does not necessarily constitute or imply its endorsement, recommendation, or favoring by the United States Government or any agency thereof. The views and opinions of authors expressed herein do not necessarily state or reflect those of the United States Government or any agency thereof.
\end{abstract}

*Managed by Lockheed Martin Energy Research Corp. for the U.S. Department of Energy under contract DE-AC05-96OR22464. 


\section{DISCLAIMER}

Portions of this document may be illegible in electronic image products. Images are produced from the best available original document. 


\title{
THE FALSTF LAST-FLIGHT COMPUTER PROGRAM
}

\author{
R. L. Childs \\ Oak Ridge National Laboratory \\ P.O. Box 2008 \\ Oak Ridge, Tennessee 37831-6370 \\ (423) $574-4121$
}

\begin{abstract}
FALSTF is a computer program used with the DORT transport code to calculate fluxes and doses at detector points located outside the DORT geometry model. An integral form of the transport equation is solved to obtain the flux at the detector points resulting from the uncollided transport of the emergent particle density within the geometry as calculated by DORT. Both R-Z and R- $\theta$ geometries are supported.
\end{abstract}

\section{INTRODUCTION}

FALSTF is a computer program used in conjunction with the DORT ${ }^{1}$ discrete-ordinates transport code to calculate dose rates and group fluxes at point detector locations specified by the user. $R-Z$ and $R-\theta$ cylindrical geometries are allowed. Mynatt ${ }^{2}$ developed the theoretical basis for FALSTF using a last-flight importance function. Next-event estimation used in Monte Carlo programs to calculate an effect of interest at point detectors is based upon the same principle. Bell and Glasstone ${ }^{3}$ derived an equation for the energydependent flux at a point by integrating the integral form of the transport equation over direction. Equation (1.29) of ref. 3 is the equation that is evaluated numerically by FALSTF for the isotropic scattering case.

The basic concept used by FALSTF is that the transport from the last collision site to the detector is done analytically rather than by using the method of discrete ordinates. This treatment gives a more accurate answer when the discrete-ordinates method is subject to ray effects or when the angular quadrature used in DORT does not have enough angles to give adequate angular resolution. The usual application of FALSTF is for detectors located in a void outside the DORT geometry. For example, FALSTF is quite useful for determining the dose $2 \mathrm{~m}$ from the surface of a cylindrical waste package or spent fuel package. FALSTF detectors can also be placed inside the DORT geometry. Detectors inside a DORT geometry containing a large cavity can sometimes be calculated more accurately with FALSTF than with DORT.

Difficulties calculating the dose $30 \mathrm{~m}$ from space reactor shields with existing methods was the motivating factor for the development of the original R-Z geometry FALSTF in 1971. Since then, FALSTF has been used (primarily at ORNL) for a number of applications, including the analysis of shielding experiments performed at the

\footnotetext{
* Mamaged by Lockheed Martin Energy Research Corp. for the U.S. Department of Energy under contract DE-AC05-960R22464.
} 
Tower Shielding Facility. These experiments included measurements of gamma-ray spectra more than $10 \mathrm{~m}$ from the shield configurations and neutron spectra more than $3 \mathrm{~m}$ away.

Several difficulties can arise in the use of the original FALSTF. Perhaps the most serious limitation is that the newer geometry input methods available in DORT, including zone specification by overlay, are not available. Also, valid DORT cross-section mixing table input can cause incorrect answers because the original FALSTF uses the obsolete requirements of DOT III. To overcome these difficulties, FALSTF has been modified extensively to provide the code described in this paper. The amount of input required has been reduced substantially by reading most of the required information from the interface file written by DORT and by removing several options deemed unlikely to be needed. The new input specifications make the preparation and checking of FALSTF input much easier and reduce the danger of incorrect results. An R- $\theta$ geometry option has also been added.

A principal motivation for updating the original FALSTF code and adding the R- $\theta$ option originated from a calculation benchmark effort completed in 1992. Within the Organization for Economic Cooperation and Development (OECD), the Nuclear Energy Agency Committee on Reactor Physics set up a working group on the shielding assessment of spent fuel transportation packages in 1985, 4 Six theoretical benchmark problems were studied by participants from 12 countries. The methods used for dose calculations included one-dimensional (I-D) and two-dimensional (2-D) discrete-ordinates, point and multigroup Monte Carlo, and kernel methods. The U.S. contribution to this study included DORT/FALSTF calculations and SAS4/MORSE ${ }^{6}$ multigroup Monte Carlo calculations. The doses calculated using DORT and FALSTF agreed quite well with those obtained from SAS4. The agreement with point Monte Carlo results was also good. Other 2-D discrete-ordinates solutions to the benchmark problems that extended the problem mesh to include the dose points had difficulties with ray effects. These problems were particularly prominent for top and bottom doses.

An alternative to the FALSTF approach is to perform a surface integration to obtain the dose at detectors in a void beyond the surface. This alternative approach was investigated, but the results discussed in Sect. 4 indicated that the method is not as accurate as the FALSTF methodology. Also, the boundary angular flux from a discrete-ordinates calculation used in the surface integration method does not provide as much information about the angular variation of the leakage flux as the volume integration method applied by FALSTF.

\section{THEORY}

In $(R, \theta, Z)$ cylindrical coordinates, the group flux at a detector point is

$$
\phi_{\operatorname{det}}=\int_{0}^{R} \int_{0}^{2 \pi} \int_{Z_{B}}^{Z_{\tau}} \frac{S_{D}(r, \theta, Z) e^{-\lambda_{D}(r, \theta, Z)}}{4 \pi\left[\rho_{D}(r, \theta, Z)\right]^{2}} \operatorname{rdrd} \theta d Z .
$$

$\phi_{\mathrm{det}}$ is the scalar flux at the detector point for the group.

$\mathrm{R}$ is the outside radius of the cylinder ( $\mathrm{a}$ void is assumed at points outside the cylinder).

$Z_{B}$ and $Z_{T}$ are the bottom and top $Z$ coordinates of the cylinder. 
$S_{D}(r, \theta, Z) / 4 \pi$ is the total source per unit volume per steradian at point $(r, \theta, Z)$ in the direction of the detector. The total source includes the distributed source, the fission source, and all scattering sources (downscatter, within-group scatter, and upscatter).

$\lambda_{D}(r, \theta, Z)$ is the distance from point $(r, \theta, Z)$ to the detector point measured in mean-free paths for the group. In FALSTF, $\lambda_{\mathrm{D}}$ is calculated by summing the product of the distance traveled in each material and the total cross section for the material.

$\rho_{D}(r, \theta, Z)$ is the distance from point $(r, \theta, Z)$ to the detector point.

In order to perform the volume integration in Eq. (1) in a 2-D, R-Z geometry, it is assumed that the source in each DORT mesh cell is a circular line source located at the radial and axial midpoint of the mesh cell. The volume integration is thus replaced by an integral over the variable $\theta$. Since DORT(R,Z) problems have azimuthal symmetry, the azimuthal location of the detector can be defined to be zero, and $\int_{0}^{2 \pi} \mathrm{d} \theta$ may be replaced with $2 \int_{0}^{\pi} \mathrm{d} \theta$. This integration is performed with a numerical quadrature.

The contribution of the source in each mesh cell is thus evaluated by summing the contribution of noa point sources, where noa is the number of terms used in the numerical quadrature.

The contribution to $\phi_{\text {det }}$ from a point source located at $\left(r, \theta_{n}, \bar{z}\right)$ is

$$
\begin{aligned}
\phi_{p} & =\frac{S_{D} e^{-\lambda_{D}}}{4 \pi \rho_{D}} \bar{r} \Delta r\left(2 \pi W_{n}\right) \Delta Z \\
& =\frac{\bar{r} \Delta r \Delta Z}{2} \frac{S_{D} e^{-\lambda_{D}}}{\rho_{D}} W_{n},
\end{aligned}
$$

where

$\bar{r}$ is the radial midpoint of the mesh cell,

$\Delta r$ is the radial thickness of the mesh cell,

$\bar{Z}$ is the axial midpoint of the mesh cell,

$\Delta Z$ is the axial thickness of the mesh cell,

$\theta_{n}$ is the nth $\theta$ location used in the quadrature integration $0 \leq \theta \leq \pi$,

$\mathrm{W}_{\mathrm{n}}$ is the $\mathrm{n}$ th weight for the quadrature integration $\left(\sum_{n=1}^{\text {NOA }} \mathrm{W}_{\mathrm{n}}=1\right)$,

$S_{D}$ is the total source per unit volume per unit sphere in the direction from the point source

to the point detector located at $\left(\mathrm{r}_{\mathrm{det}}, 0, \mathrm{Z}_{\mathrm{det}}\right)$,

$\lambda_{\mathrm{D}}$ is the distance from the point source to the point detector measured in mean-free paths (a

ray-tracing calculation is used to determine $\lambda_{d}$ ),

$\rho_{D}$ is the distance from the point source to the point detector.

The value of $S_{D}$ is obtained using the same spherical harmonics expansion used by DORT to obtain directional sources for the discrete-ordinates calculation: 


$$
S_{D}=\sum_{\ell=0}^{L} \sum_{m=0}^{\ell} \sqrt{\left(2-\delta_{0, m}\right) \frac{(l-m) !}{(l+m) !}} P_{\ell}^{m}\left(\mu_{D}\right) \cos (m \psi) S_{\ell}^{m},
$$

where

$\mu_{D}$ is the cosine of the angle between the vector, $\vec{v}_{r}$, from $(0,0, \bar{Z})$ to $\left(r, \theta_{n}, \bar{Z}\right)$ and the vector, $\overrightarrow{\mathbf{v}}_{\mathrm{D}}$, from $\left(\mathbf{r}, \theta_{\mathrm{n}}, \bar{Z}\right)$ to $\left(\mathrm{r}_{\mathrm{det}}, 0, Z_{\mathrm{det}}\right)$;

$\Psi$ is the angle between the projection of vector $\vec{v}_{D}$ onto the plane perpendicular to $\vec{v}_{r}$ and the $\mathrm{Z}$ axis;

$\mathrm{S}_{\ell}{ }^{\mathrm{m}}$ are source moments read directly from the interface file written by DORT.

Replacing the volume-distributed source for an interval with a line source can produce incorrect results when a detector is placed in or near a mesh cell that contains a source. The fact that $1 / \rho_{D}^{2}$ in Eq. (1) is a rapidly varying function of space makes the approximation invalid. FALSTF is typically used for detectors outside the DORT geometry where $\rho_{\mathrm{D}}$ is much greater than the radial or axial thickness of any mesh cell.

In R- $\theta$ geometry, it is assumed that the source in each DORT mesh cell is a line source located at the radial and $\theta$ midpoint of the mesh cell. The volume integration of Eq. (1) is replaced by an integral over the variable $Z$. This integration is performed with a numerical quadrature. Also, the $\theta$ integration from 0 to $2 \pi$ must be performed even when the DORT geometry covers only part of the angular range (a $45^{\circ}$ segment for example). Either periodic or reflected $\theta$ boundary conditions are used to extend the angular range to $2 \pi$.

Equation (3) for the source in the direction of the detector is also used in R- $\theta$ cases, but the angle $\psi$ is measured relative to a vector in the $+\theta$ direction; in the $R-Z$ case $\psi$ is measured relative to a vector in the $+Z$ direction.

\section{R-Z SAMPLE PROBLEM}

The $\mathrm{R}-\mathrm{Z}$ sample problem is the OECD problem $1 \mathrm{a}^{4,5}$ taken from the benchmark set discussed in the Introduction. Only the lid detectors are analyzed. The radius of the steel lid is $40 \mathrm{~cm}$ in the model used for these calculations. Only the top $72 \mathrm{~cm}$ of the spent fuel region was included in the model. Truncating the model at this point reduces the calculated lid doses by less than $1 \%$, while allowing a very fine mesh case to be run to study the effect of mesh size on the calculated dose. The SCALE ${ }^{7} 27-18$ group-structure is used.

Table 1 shows the effect of varying the mesh size on the centerline dose $2 \mathrm{~m}$ above the lid. Uniform meshes with equal radial and axial mesh sizes were used. The error in the calculation is reduced by roughly a factor of 4 each time the mesh size is halved. This indicates that the error is second order. It is seen that a mesh size of $0.5 \mathrm{~cm}$ has an error of $1.3 \%$.

Table 2 compares centerline point detector results from SAS4 with FALSTF results using the $0.25-\mathrm{cm}$ mesh. The agreement is quite good at $1 \mathrm{~m}$ but progressively worsens with increasing distance from the surface. Table 3 compares boundary crossing estimators from SAS4 that are averaged over the area of the cavity $(0$ to $40 \mathrm{~cm})$ with FALSTF results. The FALSTF results were obtained by placing point detectors every $4 \mathrm{~cm}$ from 0 to $40 \mathrm{~cm}$ and by performing a numerical integration. The SAS 4 result was about $5 \%$ higher than the FALSTF result at $1 \mathrm{~m}$. 
Table 1. FALSTF-calculated dose at $2 \mathrm{~m}$ above the lid vs mesh size

\begin{tabular}{lcc}
\hline $\begin{array}{c}\text { Mesh size } \\
(\mathrm{cm})\end{array}$ & Dose $(\mu \mathrm{Sv} / \mathrm{h})$ & Percent error \\
\hline 2 & 4.351 & -19.0 \\
1 & 5.089 & -5.2 \\
0.5 & 5.297 & -1.3 \\
0.25 & 5.351 & -0.3 \\
& & \\
Extrapolated & 5.369 & \\
\hline
\end{tabular}

Table 2. Centerline doses ( $\mu \mathrm{Sv} / \mathrm{h}$ ) from FALSTF and SAS4 vs distance above lid

\begin{tabular}{cccc}
\hline $\begin{array}{c}\text { Distance above lid } \\
(\mathrm{m})\end{array}$ & FALSTF & SAS4 & FALSTF/SAS4 \\
\hline 1 & 14.51 & 14.76 & 0.983 \\
2 & 5.35 & 5.59 & 0.957 \\
10 & 0.288 & 0.320 & 0.900 \\
\hline
\end{tabular}

Table 3. Doses $(\mu \mathrm{Sv} / \mathrm{h})$ radially averaged over cavity area from FALSTF and SAS4 vs distance

\begin{tabular}{cccc}
\hline $\begin{array}{c}\text { Distance above lid } \\
(\mathrm{m})\end{array}$ & FALSTF & SAS4 & FALSTF/SAS4 \\
\hline 1 & 12.79 & 13.42 & 0.953 \\
2 & 5.08 & 5.51 & 0.922 \\
3 & 2.63 & 2.86 & 0.919 \\
\hline
\end{tabular}

\section{R-O SAMPLE PROBLEM}

The DORT geometry for the R- $\theta$ sample problem is shown in Fig. 1. This shipping cask problem includes the following materials radially: fuel, SS304, aluminum, SS304, lead, concrete, SS304. The SCALE 27-18 group structure is used, but only the gamma dose is calculated. 


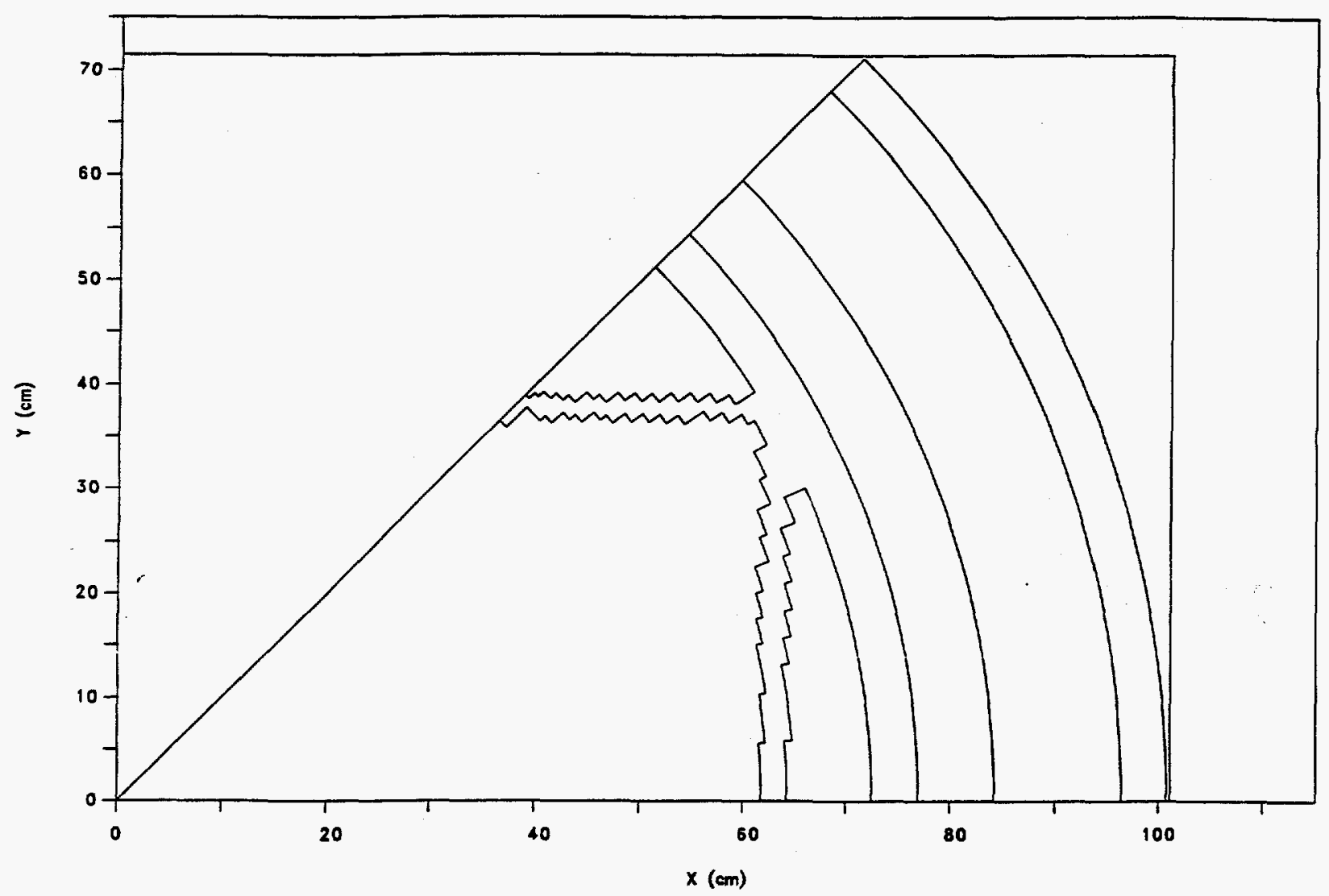

Fig. 1. The R- $\theta$ sample problem geometry.

Figure 2 shows the dose distribution at $1 \mathrm{~m}$ from the surface of a spent fuel shipping cask obtained by three different methods. All three methods use the same DORT calculation of the cask. The solid curve was obtained by extending the DORT mesh and by getting the dose values directly from DORT. The dashed curve was obtained using FALSTF. The dotted curve was obtained from a surface-integration method. The areas under the three curves differ by less than $3 \%$. This small difference indicates that the azimuthally averaged dose is about the same for all three cases even though the calculated angular distributions are very different. The DORT result is not as smooth as the other two results and has a higher peak value and a lower minimum value. The DORT and surface-integration results have local maxima near 20 and $40^{\circ}$ and a local minimum near $30^{\circ}$. The peaks appear to be ray effects resulting from the discrete angles in the angular quadrature. The FALSTF result has a maximum near $25^{\circ}$, which is where the surface peak dose occurs. Thus the FALSTF result is believed to be the best of the three, due primarily to the physical nature of the solution since experimental or Monte Carlo results are not available. 


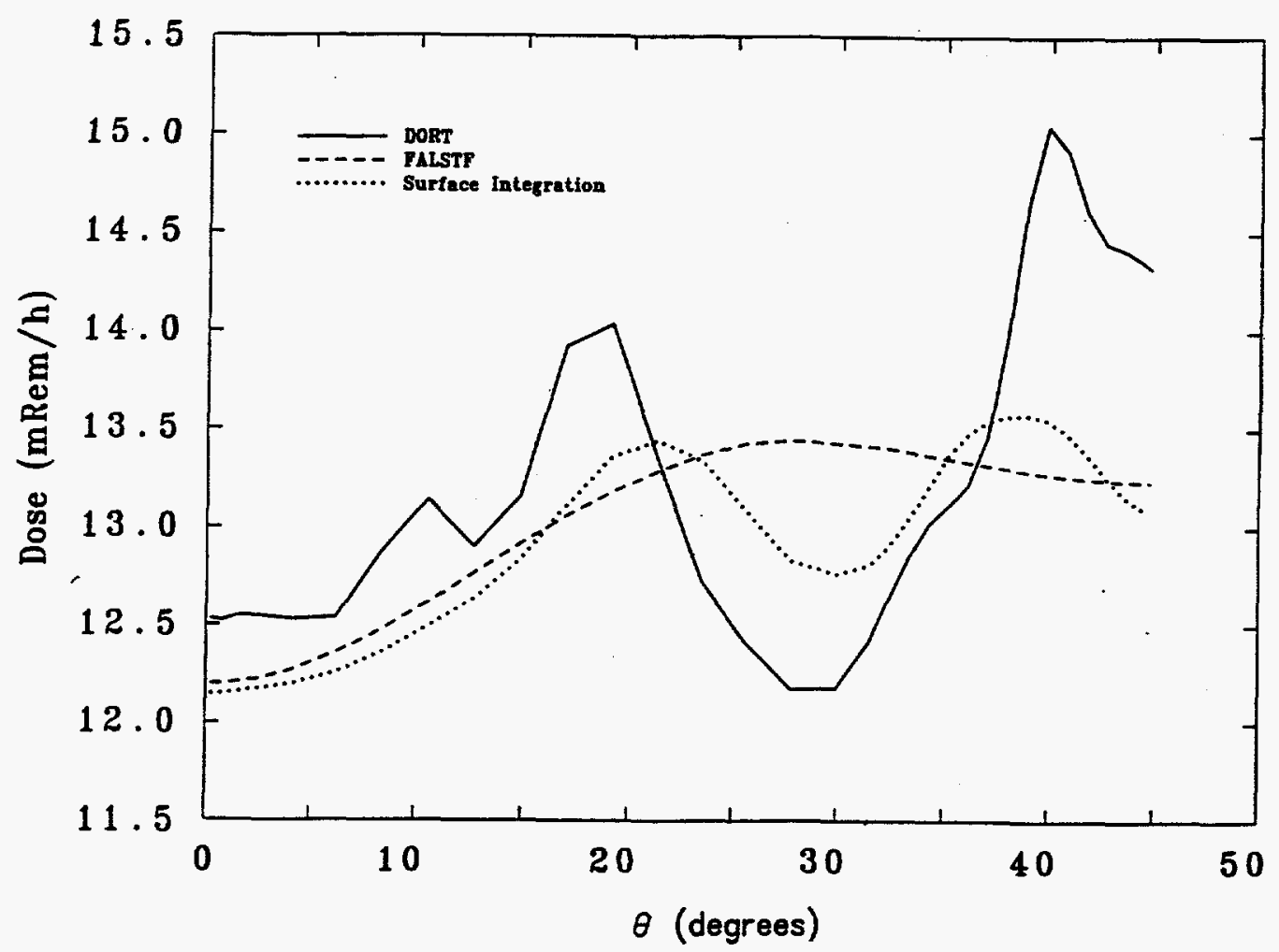

Fig. 2. Dose at $1 \mathrm{~m}$ from the surface.

\section{REFERENCES}

1. W. A. Rhoades and R. L. Childs, "The DORT Two-Dimensional Discrete Ordinates Code," Nucl. Sci. Eng. 99, 88-89 (May 1988).

2. F. R. Mynatt, F. J. Muckenthaler, and P. N. Stevens, Development of a Two-Dimensional Discrete Ordinates Transport Theory for Radiation Shielding, CTC-INF-952, Union Carbide Corp., Nucl. Div., Oak Ridge Natl. Lab. (August 1969).

3. G. I. Bell and S. Glasstone, Nuclear Reactor Theory, Van Nostrand Reinhold Co., New York, 1970.

4. B. L. Broadhead, M. C. Brady, and C. V. Parks, Benchmark Shielding Calculations for the NEACRP Working Group on Shielding Assessment of Transportation Packages, ORNL/CSD/TM-272, Martin Marietta Energy Systems, Inc., Oak Ridge Natl. Lab. (November 1990).

5. A. F. Avery and H. F. Locke, NEACRP Comparison of Codes for the Radiation Protection Assessment of Transportation Packages. Solutions to Problems 1-4, NEACRP-L-331, AEA Technology, Winfrith (March 1992). 
6. J. S. Tang, "SAS4: A Monte Carlo Cask Shielding Analysis Module Using an Automated Biasing Procedure," Sect. S4 of SCALE: A Modular Code System for Performing Standardized Computer Analyses for Licensing Evaluation, NUREG/CR-0200, Rev. 4 (ORNL/NUREG/ CSD-2/R4), Vols. I, II, and III (draft February 1990). Available from Radiation Shielding Information Center as CCC-545.

7. SCALE: A Modular Code System for Performing Standardized Computer Analyses for Licensing Evaluation, Vols. I-III, NUREG/CR-0200, Rev. 4 (ORNL/NUREG/CSD-2/R4), (April 1995). Available from Radiation Shielding Information Center as CCC-545. 